\title{
EFFECTS OF DESIGN PARAMETERS ON STATIC EQUIVALENT STRESS OF RADIAL ROLLING BEARINGS
}

\author{
MeHMET BozCA \\ Yildiz Technical University, Mechanical Engineering Faculty, Machine Design Division, 34349 Yildiz, Istanbul, \\ Turkey \\ correspondence: mbozca@yildiz.edu.tr
}

\begin{abstract}
The aim of this study is to theoretically investigate the effects of design parameters on the static equivalent stress of radial rolling bearings, such as the point contact case for ball bearings and line contact case for roller bearings. The contact pressure, contact area and von Misses stress of bearings are calculated based on geometrical parameters, material parameters and loading parameters by using the developed MATLAB program. To achieve this aim, both the maximum contact pressure $p_{\max }$ and Von Mises effective stress $\sigma_{V M}$ are simulated with respect to design parameters such as varying ball and roller element diameters and varying ball and roller element elasticity modulus. For the point contact case and line contact case, it was concluded that increasing the diameter of ball and roller elements results in reducing the maximum contact pressure $p_{\max }$ and Von Mises effective stress $\sigma_{V M}$. Furthermore, increasing the elasticity modulus of the ball and roller elements results in increasing the maximum contact pressure $p_{\max }$ and Von Mises effective stress $\sigma_{V M}$ because of the decrease of contact area $A$. The determination of the diameter of the ball and roller elements and the selection of material are crucial and play an effective role during the design process. Therefore, bearing designers and manufacturers should make the bearing geometrical dimensions as large as possible and bearing material as elastic as possible. Furthermore, the stress-based static failure theory can also be used instead of the standard static load carrying capacity calculation. Moreover, Von Mises stress theory is also compatible with the finite element method.
\end{abstract}

KEYwORDS: Ball bearing, point contact, roller bearing, line contact, contact pressure, Von Mises stress.

\section{INTRODUCTION}

Rolling bearings such as ball and roller bearings are widely used for rotating machines in industry. A surface failure can occur during point contact in ball bearing applications. Point contact results in a contact pressure and contact stress between two spherical surfaces. Similarly, the surface failure can occur during line contact in roller bearing applications. Line contact results in a contact pressure and contact stress between two cylindrical surfaces.

The purpose of this study is a theoretical investigation of the effects of design parameters on static equivalent stress of radial rolling bearings, such as ball bearings and roller bearing. For this purpose, the maximum contact pressure $p_{\max }$ and Von Mises effective stress are calculated with respect to varying design parameters.

The following studies focused on load carrying capacity and fatigue life of rolling bearing, based on Hertzian contact stress.

Rolling contact fatigue results in metallic particles flaking from the surface of the ball and rolling elements or raceways. Neglecting lubrication effects, the stress in a bearing contact is governed by the Hertzian theory [1.

The calculation of load carrying capacity of standard bearings is widely known and standardized by standard organizations, such as ISO and DIN, and it is based on the Hertzian theory of contact [2].

The life of a rolling bearing has been modelled using basic principles of rolling contact fatigue based on an equivalent stress originating beneath the contacting surface [3].

Developed high-speed angular contact ball bearing products feature improved internal design, including rolling elements of increased diameter. Thus, the load rating has been improved, and the allowable load has been increased [4].

Point contact for ball bearings application was investigated theoretically, and the effects of the ball bearing's geometry and material on the ball bearing stress were presented. Increasing the ball element's diameter results in a reduced ball bearing stress. In contrast, the increasing elasticity modulus results in an increased ball bearing stress $[6$.

Line contact for roller bearings application was investigated theoretically, and the effects of the roller bearing's geometry and material on the roller bearing stress were presented. Increasing the roller element's diameter results in a reduced ball bearing stress. However, increasing the elasticity modulus of the roller elements results in an increased roller bearing stress [7].

The contact stress in rolling bearings, determined by using analytical and numerical methods, was pre- 


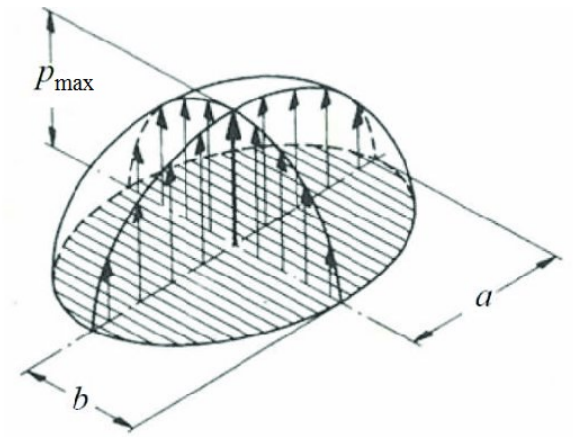

(A) . 3D distribution of surface pressure for point contact 5].

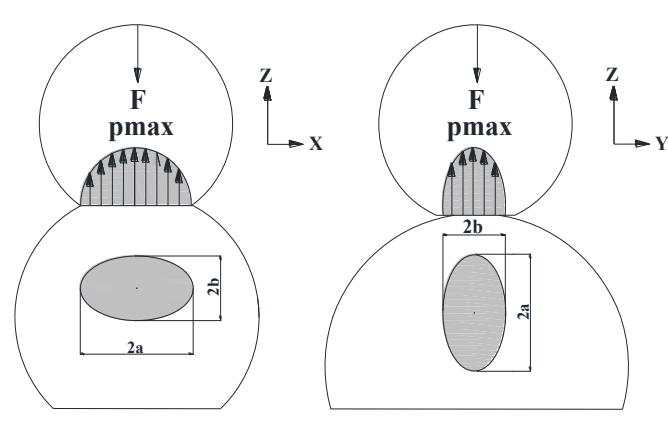

(B) . 2D distribution of surface pressure for point contact.

Figure 1.

sented. The analytical solution is obtained by using Hertizan contact theory. The same problems are also examined by using the finite element method to examine the contact analysis of a rolling bearing. The normal and tangential forces as well as the rolling friction between mated parts are analysed in order to obtain more accurate results. A numerical analysis of contact problems by computer programs gives more accurate results [8].

The effect of the internal radial clearance on the damping characteristics, natural modes of vibration, and fatigue life of rolling element bearings was studied. It was concluded that the experimental results showed that the bearing with the largest radial clearance had the lowest damping ratio, highest natural frequency, and shortest bearing life [9].

The effect of the internal clearance on radially loaded deep groove ball and cylindrical roller bearing load distribution and fatigue life was determined for different clearance groups. The analysis was extended to negative clearance conditions to produce a curve of the life factor versus the internal clearance. It was concluded that rolling-element loads can be optimized and bearing life maximized for a small negative operating clearance. The life shortens gradually with a positive clearance and rapidly with an increasing negative clearance [10].

An experimental procedure for predicting the fatigue life of each individual rolling element bearing separately using a vibration modal analysis was presented. A statistical analysis was performed to find an empirical model that correlates the dynamic load capacity of rolling bearings to their dynamic characteristics such as natural frequencies and damping. A modified formula to the already known LundbergPalmgren life formula is proposed for rolling element bearings. Given the modified formula, one can predict the fatigue life of each individual rolling element bearing based on its dynamic characteristics [11].

An optimisation algorithm developed for an optimal axial preload of a rolling bearings system that consists of two angular contact ball bearings or tapered bearings to maximize the bearing's life. The Lundberg and Palmgren model is used to evaluate the rolling bearing's life. It was concluded that using the Lundberg and Palmgren model, it is obvious that the axial bearing preload influences the bearing's fatigue life and the optimal preload value can be determined [12].

\section{Contact PRESSURE AND STRESS}

\subsection{BALL BEARING APPLICATION}

For the ball bearing application case, the point contact pressure and Von Mises effective stress are calculated.

\subsubsection{Point CONTACT PRESSURE}

The contact pressure is maximum $p_{\max }$ at the centre and zero at the edge, as shown in Figure 1a and Figure $1 \mathrm{~b}$. The total applied load $F$ on the contact patch is equal to the volume of the hemisphere. The total applied load $F$ is written as follows [5, 13-17]:

$$
F=\frac{2}{3} \pi a^{2} p_{\max }
$$

where $a$ is the half-width (radius) of the contact patch as shown in Figure $1 \mathrm{a}$ and Figure $1 \mathrm{~b}$. This can be solved for the maximum pressure:

$$
p_{\max }=\frac{3}{2} \frac{F}{\pi a^{2}}
$$

The average pressure on the contact patch is the applied force divided by its area:

$$
p_{\text {avg }}=\frac{F}{\text { area }}=\frac{F}{\pi a^{2}}
$$

Then, the maximum pressure can be re-arranged as follows:

$$
p_{\max }=\frac{3}{2} p_{\text {avg }}
$$

The material constants $m_{1}$ and $m_{2}$ for the two spheres are defined as follows:

$$
m_{1}=\frac{1-\nu_{1}^{2}}{E_{1}}
$$

and

$$
m_{2}=\frac{1-\nu_{2}^{2}}{E_{2}}
$$

where $\nu_{1}, \nu_{2}$ are the Poisson's ratios, and $E_{1}, E_{2}$ are the Young's moduli for the materials. 


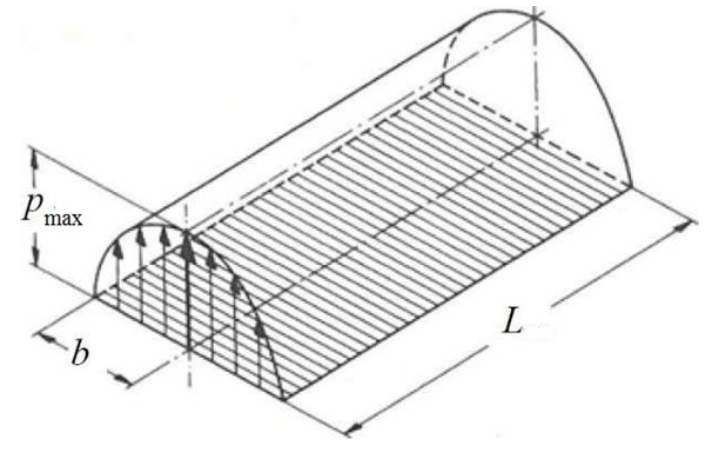

(A) . 3D Distribution of surface pressure for line contact [5].

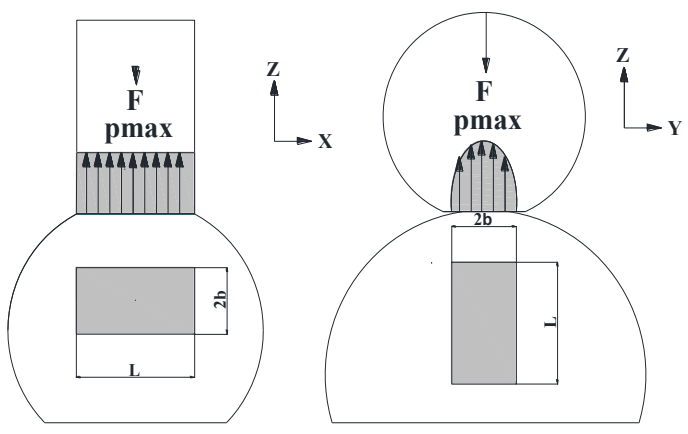

(в) . 2D distribution of surface pressure for line contact.

Figure 2 .

A geometry constant $\Re$ that depends only on the radii $R_{1}$ and $R_{2}$ of the two spheres can be defined as follows:

$$
\Re=\frac{1}{2}\left(\frac{1}{R_{1}}+\frac{1}{R_{2}}\right)
$$

The contact-patch radius $a$ is then found from

$$
a=\frac{\pi}{4} p_{\max }\left(\frac{m_{1}+m_{2}}{\Re}\right)
$$

By substituting equation (2) in equation (8), equation $\sqrt{9}$ is written as follows:

$$
a=\sqrt[3]{0.375\left(\frac{m_{1}+m_{2}}{\Re}\right) F}
$$

The pressure distribution within the hemisphere is

$$
p=p_{\max } \sqrt{1-\frac{x^{2}}{a^{2}}-\frac{y^{2}}{a^{2}}}
$$

\subsubsection{POINT CONTACT STRESS}

The stresses that are maximal at the surface at which $z=0$ are written as follows [5, 13, 17]:

$$
\begin{gathered}
\sigma_{z \max }=-p_{\max } \\
\sigma_{x \max }=\sigma_{y \max }=-\left(\frac{1+2 \nu}{2}\right) p_{\max } \\
\tau_{x y}=\left(\frac{1+2 \nu}{3}\right) p_{\max }
\end{gathered}
$$

\subsubsection{Von Mises effective stress}

Von Mises effective stress is written according to the applied stresses as follows [5, 13,17]:

$\sigma_{V M}=\frac{1}{\sqrt{2}} \sqrt{\left(\sigma_{x}-\sigma_{y}\right)^{2}+\left(\sigma_{y}-\sigma_{z}\right)^{2}+\left(\sigma_{z}-\sigma_{x}\right)^{2}+6\left(\tau_{x y}^{2}+\tau_{y z}^{2}+\tau_{z x}^{2}\right)}$

A stress-based failure criterion for a static loading condition is considered during the design stage as follows:

$$
\sigma_{V M} \leq S_{y}
$$

where $S_{y}$ is the yield strength of the bearing material. The yield strength point is considered as the failure limit during static loading conditions.

\subsection{ROLLER BEARING APPLICATION}

For the roller bearing application case, the line contact pressure and Von Mises effective stress are calculated.

\subsubsection{LINE CONTACT PRESSURE}

The contact pressure is maximum $p_{\max }$ at the centre and zero at the edges, as shown in Figure $2 \mathrm{a}$ and Figure $2 \mathrm{~b}$ The applied load $F$ on the contact patch is equal to the volume of the half-prism [5, 13, 17].

$$
F=\frac{1}{2} \pi a L p_{\max }
$$

where $F$ is the total applied load and $L$ is the length of the contact along the cylinder axis as shown in Figure $2 \mathrm{a}$ and Figure $2 \mathrm{~b}$, This can be solved for the maximum pressure:

$$
p_{\max }=\frac{2 F}{\pi a L}
$$

The average pressure is the applied force divided by the contact-patch area:

$$
p_{\text {avg }}=\frac{F}{\text { area }}=\frac{F}{2 a L}
$$

The applied force can be written as a function of the average pressure:

$$
F=2 a L\left(p_{a v g}\right)
$$

Then, the maximum pressure can be re-arranged as follows:

$$
p_{\max }=\frac{4}{\pi} p_{a v g} \approx 1.273 p_{\text {avg }}
$$

We now define a cylindrical geometry constant $\Re$ that depends on the radii $R_{1}$ and $R_{2}$ of the two cylinders:

$$
\Re=\frac{1}{2}\left(\frac{1}{R_{1}}+\frac{1}{R_{2}}\right)
$$

The contact-patch half width $a$ is then found from

$$
a=\sqrt{\frac{2}{\pi} \frac{m_{1}+m_{2}}{\Re} \frac{F}{L}}
$$

where $m_{1}$ and $m_{2}$ are material constants defined in the following equations:

$$
m_{1}=\frac{1-\nu_{1}^{2}}{E_{1}}
$$


and

$$
m_{2}=\frac{1-\nu_{2}^{2}}{E_{2}}
$$

where $\nu_{1}, \nu_{2}$ are the Poisson's ratios and $E_{1}, E_{2}$ are the Young's moduli for the materials. The pressure distribution within the semi-elliptical prism is

$$
p=p_{\max } \sqrt{1-\frac{x^{2}}{a^{2}}}
$$

\subsubsection{LINE CONTACT STRESS}

The stresses due to the normal loading $p_{\max }$ are written as follows [5, 13, 17]:

$$
\begin{gathered}
\sigma_{x n}=-p_{\max } \sqrt{1-\frac{x^{2}}{a^{2}}} \\
\sigma_{z n}=-p_{\max } \sqrt{1-\frac{x^{2}}{a^{2}}} \\
\tau_{x z n}=0
\end{gathered}
$$

\subsubsection{Von Mises effective Stress}

Von Mises effective stress is written according to the applied stresses as follows [5, 13, 17]:

$$
\sigma_{V M}=\sqrt{\sigma_{x}^{2}+\sigma_{z}^{2}-\sigma_{x} \sigma_{z}+3 \tau_{x z}^{2}}
$$

A stress-based failure criterion for static loading conditions is considered during the design stage as follows:

$$
\sigma_{V M} \leq S_{y}
$$

where $S_{y}$ is yield strength of the bearing material. The yield strength point is considered as the failure limit during the static loading condition.

\section{NUMERICAL RESULTS}

A radial ball bearing and a radial roller bearing are considered in the numerical examples. The contact pressure, contact area and von Misses stress of bearings are calculated based on geometrical parameters, material parameters and loading parameters by using MATLAB program. A flow chart of the calculation algorithm is shown in Figure 3.

\subsection{EXAMPLE OF BALL BEARING APPLICATION}

In the numerical example for a ball bearing shown in Figure 4 the maximum contact pressure and Von Mises stress are simulated by varying the radius and elasticity modulus of the ball element. The results of the simulation for a varying radius of the ball element are reported in Table 1 .

Increasing the radius of the ball element $R_{1}$ results in an increased contact area $A$, as shown in Figure 5 .

Increasing the radius of the ball element results in a reduced maximum contact pressure $p_{\max }$, as shown in Figure 6

Increasing the radius of the ball element results in a reduced Von Mises stress $\sigma_{V M}$, as shown in Figure 7

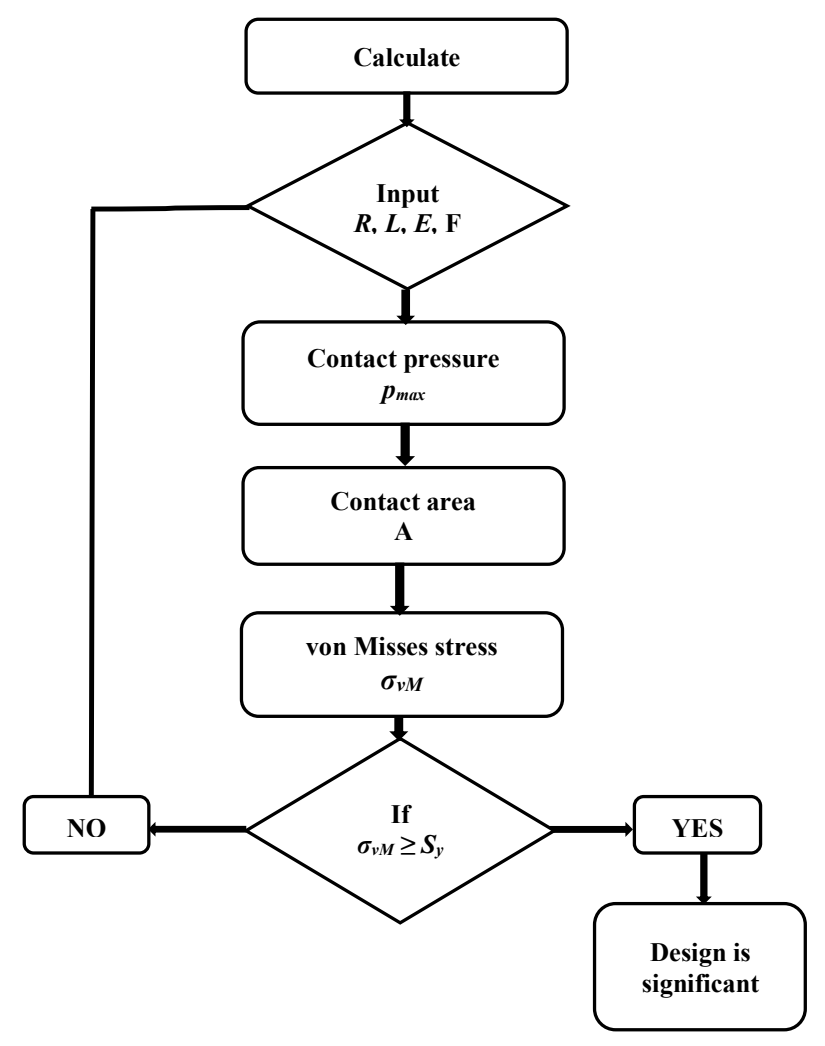

Figure 3. Flow chart of the von Mises stress calculation of a roller bearing.

The simulation results for a varying elasticity modulus of the ball element are presented in Table 2

Increasing the elasticity modulus of the ball element results in a decreased contact area $A$, as shown in Figure 8

Increasing the elasticity modulus of the ball element results in an increased maximum contact pressure $p_{\max }$, as shown in Figure 9

Increasing the elasticity modulus of the ball element results in an increased Von Mises stress $\sigma_{V M}$, as shown in Figure 10.

\subsubsection{EXAMPLE OF A STANDARD BALL BEARING}

A numerical example of a standard ball bearing is performed for the 6014 ball bearing, as shown in Figure 11 Basic dimensions of the 6014 ball bearing are presented in Table 3

The maximum contact pressure $p_{\max }$ and Von Misses stress $\sigma_{V M}$ of 6014 ball bearings are calculated. The obtained results are presented in Table 4 It is shown that increasing the radius of the ball element results in a reduced the Von Mises stress $\sigma_{V M}$, since the standard ball bearing ball radius is larger than the simulation values of the ball radius.

\subsection{EXAMPLE OF ROLLER BEARING APPLICATION}

In the numerical example for a roller bearing shown in Figure 12 the average contact pressure, maximum contact pressure and Von Mises stress are simulated 

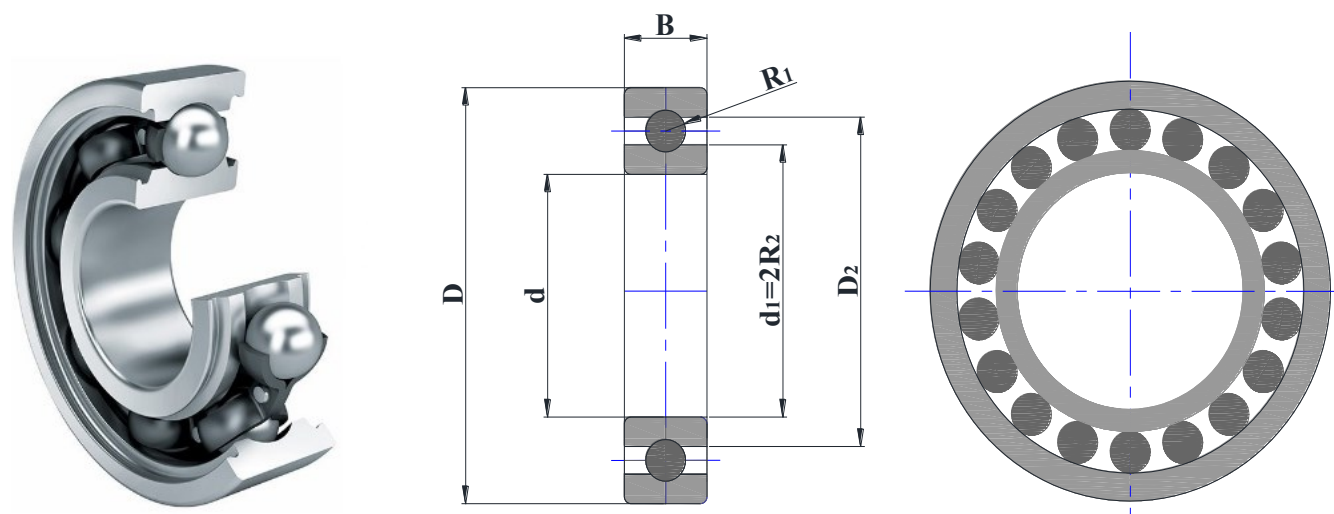

FiguRE 4. Ball bearing.

\begin{tabular}{ccccccc}
\hline $\begin{array}{c}R_{1} \\
{[\mathrm{~mm}]}\end{array}$ & $\begin{array}{c}R_{2} \\
{[\mathrm{~mm}]}\end{array}$ & $\begin{array}{c}\Re \\
{\left[\mathrm{mm}^{-1}\right]}\end{array}$ & $\begin{array}{c}a \\
{[\mathrm{~mm}]}\end{array}$ & $\begin{array}{c}A \\
{\left[\mathrm{~mm}^{2}\right]}\end{array}$ & $\begin{array}{c}p_{\max } \\
{[\mathrm{MPa}]}\end{array}$ & $\begin{array}{c}\sigma_{V M} \\
{[\mathrm{MPa}]}\end{array}$ \\
\hline 3.00 & 40 & 0.1792 & 0.4512 & 0.6396 & 11727 & 3940 \\
3.50 & 40 & 0.1554 & 0.4732 & 0.7033 & 10663 & 3583 \\
4.00 & 40 & 0.1375 & 0.4928 & 0.7630 & 9829 & 3302 \\
4.50 & 40 & 0.1236 & 0.5106 & 0.8191 & 9156 & 3076 \\
5.00 & 40 & 0.1125 & 0.5296 & 0.8722 & 8598 & 2889 \\
5.50 & 40 & 0.1034 & 0.5419 & 0.9226 & 8129 & 2731 \\
6.00 & 40 & 0.0958 & 0.5558 & 0.9706 & 7727 & 2596 \\
\hline
\end{tabular}

TABLE 1. Contact pressure and Von Mises stress results for a varying radius of the ball element.

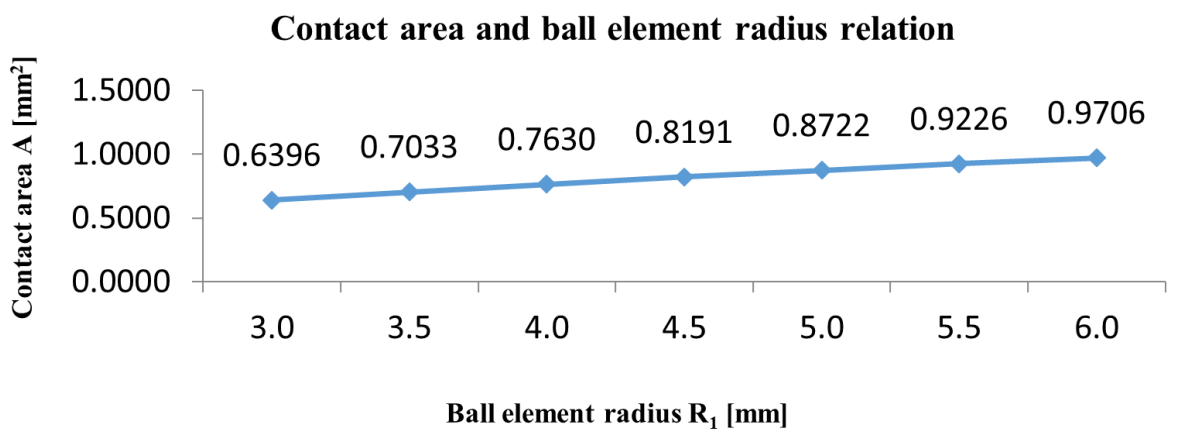

FiguRE 5. Relation between the contact area and the radios of the ball element.

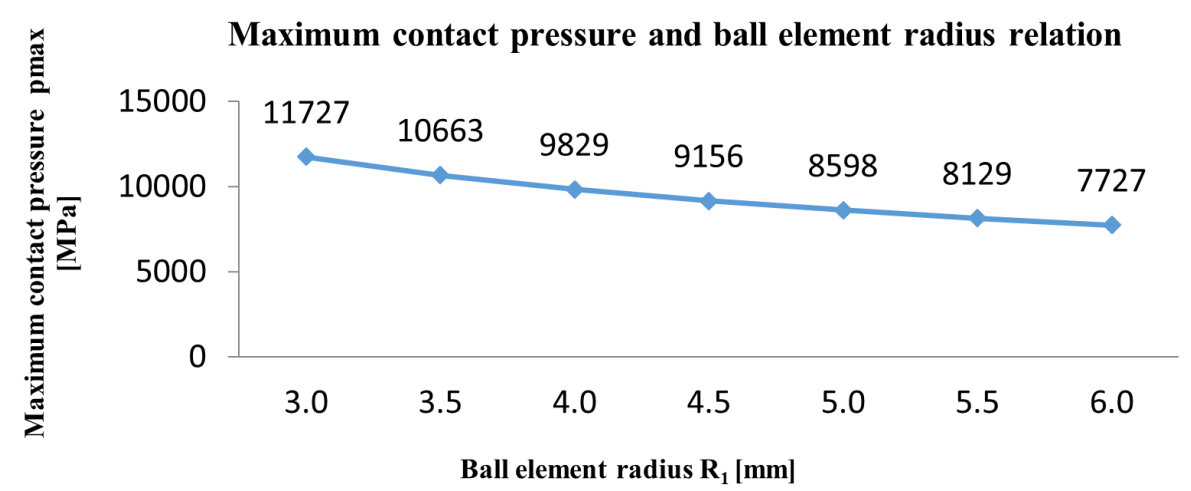

FiguRE 6. Relation between the maximum contact pressure and the radius of the ball element. 


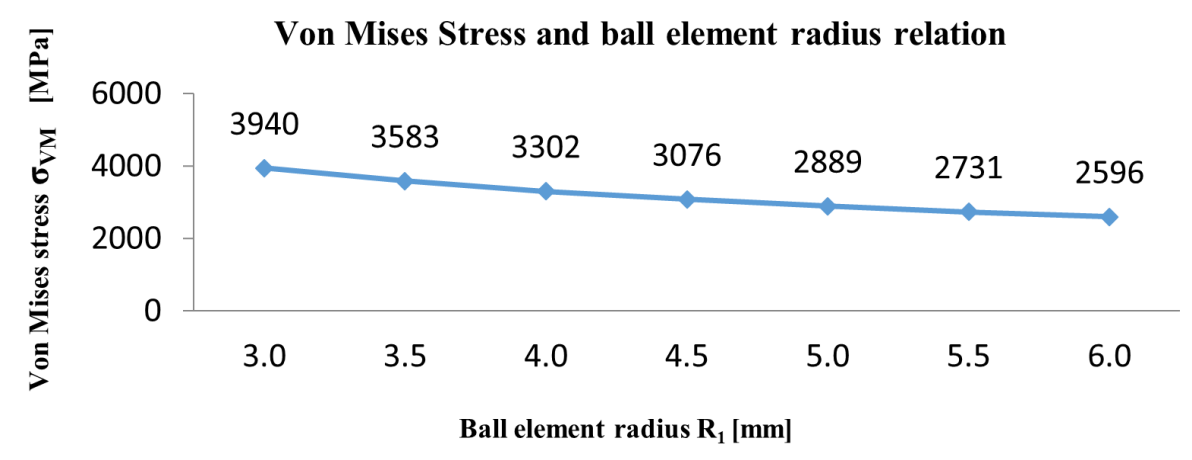

Figure 7. Relation between Von Mises stress and the radius of the ball element.

\begin{tabular}{ccccccc}
\hline $\begin{array}{c}E_{1} \\
{[\mathrm{MPa}]}\end{array}$ & $\begin{array}{c}E_{2} \\
{[\mathrm{MPa}]}\end{array}$ & $\begin{array}{c}\Re \\
{\left[\mathrm{mm}^{-1}\right]}\end{array}$ & $\begin{array}{c}a \\
{[\mathrm{~mm}]}\end{array}$ & $\begin{array}{c}A \\
{\left[\mathrm{~mm}^{2}\right]}\end{array}$ & $\begin{array}{c}p_{\max } \\
{[\mathrm{MPa}]}\end{array}$ & $\begin{array}{c}\sigma_{V M} \\
{[\mathrm{MPa}]}\end{array}$ \\
\hline 180000 & 210000 & 0.1125 & 0.5412 & 0.9200 & 8152 & 2739 \\
190000 & 210000 & 0.1125 & 0.5360 & 0.9025 & 8309 & 2792 \\
200000 & 210000 & 0.1125 & 0.5313 & 0.8867 & 8458 & 2842 \\
210000 & 210000 & 0.1125 & 0.5269 & 0.8722 & 8598 & 2889 \\
220000 & 210000 & 0.1125 & 0.5229 & 0.8589 & 8731 & 2933 \\
230000 & 210000 & 0.1125 & 0.5192 & 0.8467 & 8857 & 2976 \\
240000 & 210000 & 0.1125 & 0.5157 & 0.8355 & 8977 & 3016 \\
\hline
\end{tabular}

TABLE 2. Contact pressure and Von Mises stress for a varying elasticity modulus of the ball element.

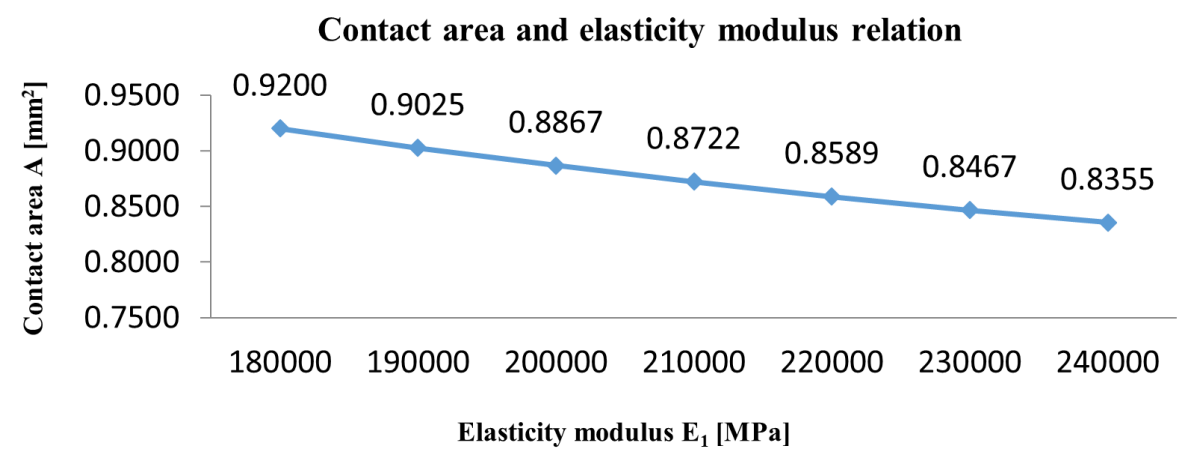

Figure 8. Relation between the contact area and elasticity modulus.

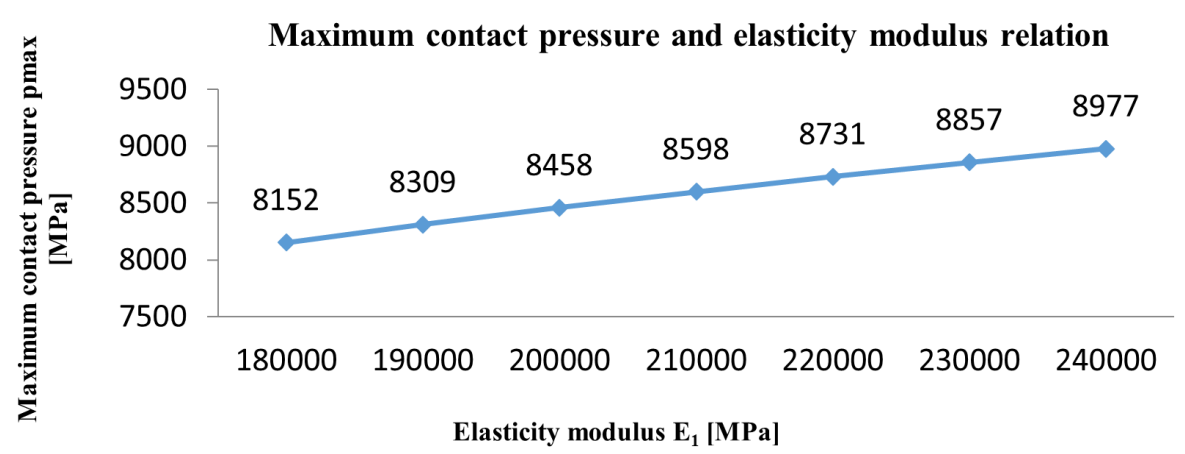

FiguRE 9. Relation between the maximum contact pressure and elasticity modulus.

\begin{tabular}{ccccc}
\hline $\begin{array}{c}d \\
{[\mathrm{~mm}]}\end{array}$ & $\begin{array}{c}D \\
{[\mathrm{~mm}]}\end{array}$ & $\begin{array}{c}B \\
{[\mathrm{~mm}]}\end{array}$ & $\begin{array}{c}d_{1} \\
{[\mathrm{~mm}]}\end{array}$ & $\begin{array}{c}D_{2} \\
{[\mathrm{~mm}]}\end{array}$ \\
\hline 70 & 110 & 20 & 82.85 & 99.9 \\
\hline
\end{tabular}

TABLE 3. Basic dimensions of standard 6014 ball bearing. 


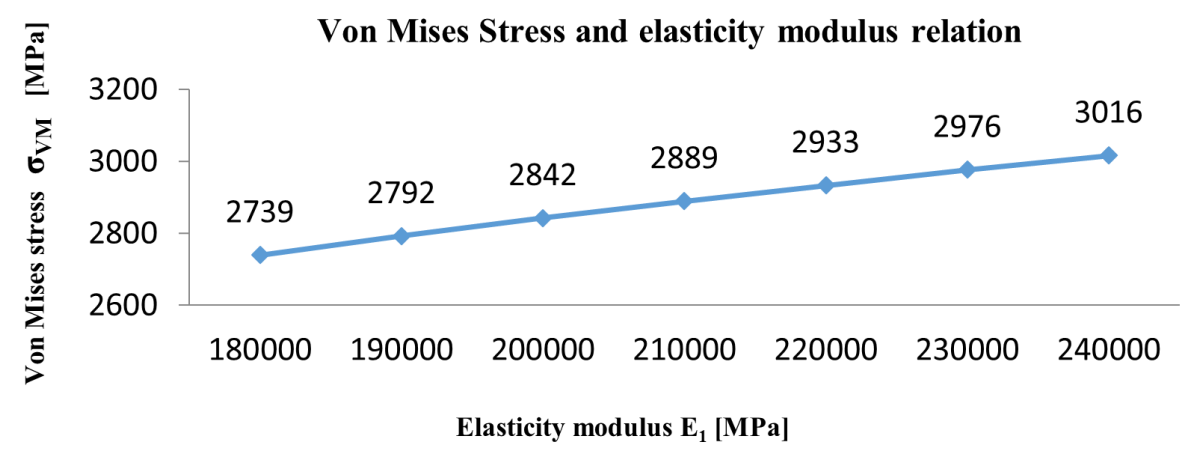

Figure 10. Von Mises stress and elasticity modulus relation.

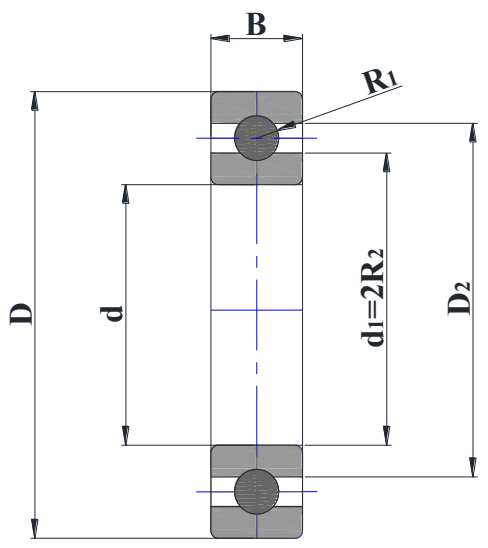

Figure 11. Basic Dimensions of 6014 ball bearing.

by varying the radius and elasticity modulus of the roller element. The simulation results for a varying radius of the roller element are reported in Table 5

Increasing the radius of the roller element results in an increased contact area $A$, as shown in Figure 13

Increasing the radius of the roller element results in a decreased maximum contact pressure $p_{\max }$, as shown in Figure 14.

Increasing the radius of the roller element results in a decreased Von Mises stress $\sigma_{V M}$, as shown in Figure 15

The simulation results for a varying elasticity modulus of the roller element are reported in Table 6

Increasing the elasticity modulus of the roller element results in a decreased contact area $A$, as shown in Figure 16.

Increasing the elasticity modulus of the roller element results in an increased maximum contact pressure $p_{\max }$, as shown in Figure 17.

Increasing the elasticity modulus of the roller element results in an increased Von Mises stress, as shown in Figure 18.

3.2.1. EXAMPLE OF A STANDARD ROLLER BEARING A numerical example of a standard roller bearing is performed for NU 1014 roller bearing, as shown in Figure 19. Basic dimensions of NU 1014 roller bearing are presented in Table 7

The maximum contact pressure $p_{\max }$ and von Misses stress $\sigma_{V M}$ of NU 1014 roller bearings are calculated. The obtained results are presented in Table 8 . It is shown that increasing the radius of the roller element results in a reduced the Von Mises stress $\sigma_{V M}$ since the standard radius of a roller bearing is larger than the simulation values of the roller radius.

\section{Discussion}

Increasing the radius of the ball element $R_{1}$ from $3[\mathrm{~mm}]$ to $6[\mathrm{~mm}]$ results in an increased contact area $A$ from $0.6396\left[\mathrm{~mm}^{2}\right]$ to $0.9706\left[\mathrm{~mm}^{2}\right]$ while reducing the geometry constant from $0.1792\left[\mathrm{~mm}^{-1}\right]$ to $0.0958\left[\mathrm{~mm}^{-1}\right]$. In contrast, increasing the radius of the ball element $R_{1}$ results in an increased contactpatch radius a from $0.4512[\mathrm{~mm}]$ to $0.5558[\mathrm{~mm}]$, as reported Table 1

Increasing the elasticity modulus of the ball element $E_{1}$ from $180000\left[\mathrm{~N} / \mathrm{mm}^{2}\right]$ to $240000\left[\mathrm{~N} / \mathrm{mm}^{2}\right]$ results in a decreased contact area A from $0.9200\left[\mathrm{~mm}^{2}\right]$ to $0.8355\left[\mathrm{~mm}^{2}\right]$ while keeping the geometry constant as constant. In contrast, increasing the elasticity modulus of the ball $E_{1}$ results in a decreased contactpatch radius a from $0.5412[\mathrm{~mm}]$ to $0.5157[\mathrm{~mm}]$, as reported in Table 2 .

Increasing the radius of the roller element $R_{1}$ from $3[\mathrm{~mm}]$ to $6[\mathrm{~mm}]$ results in an increased contact area $A$ from $2.4975\left[\mathrm{~mm}^{2}\right]$ to $3.4149\left[\mathrm{~mm}^{2}\right]$ while decreasing the geometry constant from $0.1792\left[\mathrm{~mm}^{-1}\right]$ to $0.0958\left[\mathrm{~mm}^{-1}\right]$. In contrast, increasing the radius of the roller element $R_{1}$ results in an increased contact- 


\begin{tabular}{ccccccc}
\hline $\begin{array}{c}R_{1} \\
{[\mathrm{~mm}]}\end{array}$ & $\begin{array}{c}R_{2} \\
{[\mathrm{~mm}]}\end{array}$ & $\begin{array}{c}\Re \\
{\left[\mathrm{mm}^{-1}\right]}\end{array}$ & $\begin{array}{c}a \\
{[\mathrm{~mm}]}\end{array}$ & $\begin{array}{c}A \\
{\left[\mathrm{~mm}^{2}\right]}\end{array}$ & $\begin{array}{c}p_{\max } \\
{[\mathrm{MPa}]}\end{array}$ & $\begin{array}{c}\sigma_{V M} \\
{[\mathrm{MPa}]}\end{array}$ \\
\hline 8.00 & 40 & 0.0750 & 0.6032 & 1.1429 & 6562 & 2204 \\
\hline
\end{tabular}

TABle 4. Contact pressure and Von Mises stress results for standard 6014 ball bearing.
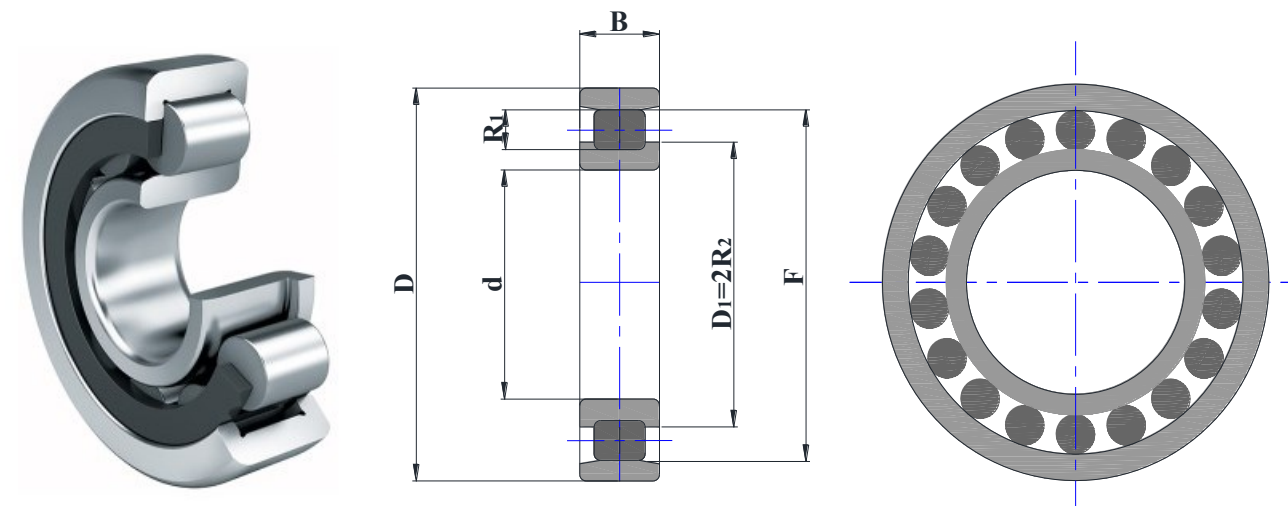

FiguRe 12. Roller bearing.

\begin{tabular}{ccccccc}
\hline $\begin{array}{c}R_{1} \\
{[\mathrm{~mm}]}\end{array}$ & $\begin{array}{c}R_{2} \\
{[\mathrm{~mm}]}\end{array}$ & $\begin{array}{c}\Re \\
{\left[\mathrm{mm}^{-1}\right]}\end{array}$ & $\begin{array}{c}a \\
{[\mathrm{~mm}]}\end{array}$ & $\begin{array}{c}A \\
{\left[\mathrm{~mm}^{2}\right]}\end{array}$ & $\begin{array}{c}p_{\max } \\
{[\mathrm{MPa}]}\end{array}$ & $\begin{array}{c}\sigma_{V M} \\
{[\mathrm{MPa}]}\end{array}$ \\
\hline 3.00 & 40 & 0.1792 & 0.1249 & 2.4975 & 2549 & 4211 \\
3.50 & 40 & 0.1554 & 0.1341 & 2.6820 & 2373 & 3921 \\
4.00 & 40 & 0.1375 & 0.1425 & 2.8509 & 2233 & 3689 \\
4.50 & 40 & 0.1236 & 0.1503 & 3.0068 & 2117 & 3498 \\
5.00 & 40 & 0.1125 & 0.1576 & 3.1518 & 2019 & 3337 \\
5.50 & 40 & 0.1034 & 0.1644 & 3.2874 & 1936 & 3199 \\
6.00 & 40 & 0.0958 & 0.1707 & 3.4149 & 1864 & 3080 \\
\hline
\end{tabular}

TABLE 5. Contact pressure and Von Mises stress results for a varying radius of the roller element.

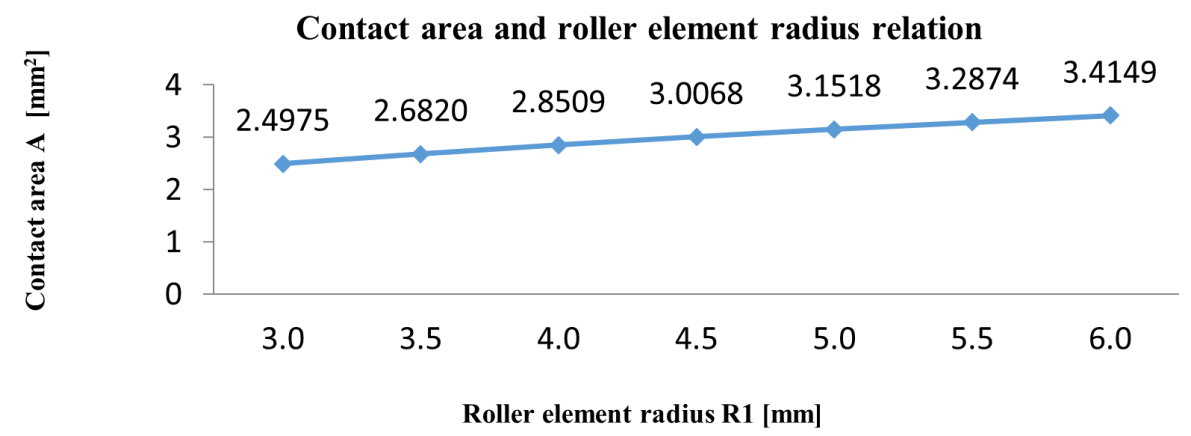

Figure 13. Relation between the contact area and the radius of the roller element.

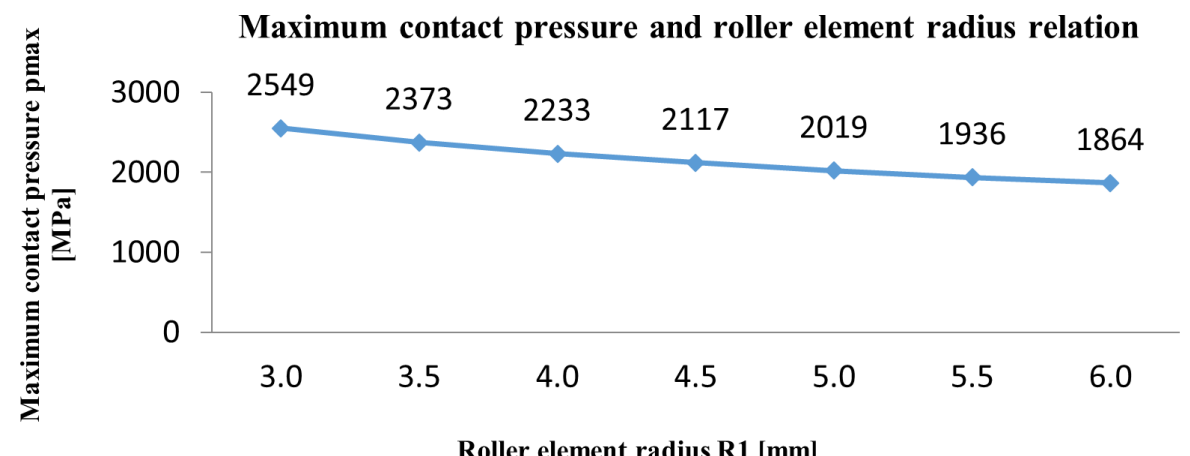

FIGURE 14. Relation between the maximum contact pressure and the radius of the roller element. 


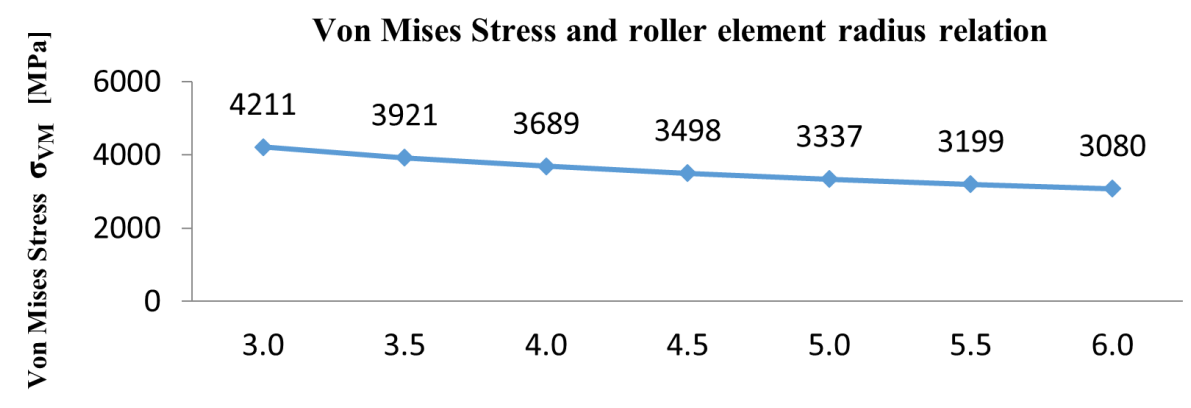

Roller element radius $\mathbf{R} 1[\mathrm{~mm}]$

Figure 15. Relation between Von Mises stress and the radius of the roller element.

\begin{tabular}{ccccccc}
\hline $\begin{array}{c}E_{1} \\
{[\mathrm{MPa}]}\end{array}$ & $\begin{array}{c}E_{2} \\
{[\mathrm{MPa}]}\end{array}$ & $\begin{array}{c}\Re \\
{\left[\mathrm{mm}^{-1}\right]}\end{array}$ & $\begin{array}{c}a \\
{[\mathrm{~mm}]}\end{array}$ & $\begin{array}{c}A \\
{\left[\mathrm{~mm}^{2}\right]}\end{array}$ & $\begin{array}{c}p_{\max } \\
{[\mathrm{MPa}]}\end{array}$ & $\begin{array}{c}\sigma_{V M} \\
{[\mathrm{MPa}]}\end{array}$ \\
\hline 180000 & 210000 & 0.1125 & 0.1640 & 3.2805 & 1940 & 3206 \\
190000 & 210000 & 0.1125 & 0.1617 & 3.2337 & 1968 & 3252 \\
200000 & 210000 & 0.1125 & 0.1595 & 3.1909 & 1995 & 3296 \\
210000 & 210000 & 0.1125 & 0.1576 & 3.1518 & 2019 & 3337 \\
220000 & 210000 & 0.1125 & 0.1558 & 3.1158 & 2043 & 3376 \\
230000 & 210000 & 0.1125 & 0.1541 & 3.0825 & 2065 & 3412 \\
240000 & 210000 & 0.1125 & 0.1526 & 3.0517 & 2086 & 3446 \\
\hline
\end{tabular}

TABLE 6. Contact pressure and Von Mises stress for a varying elasticity modulus of the roller element.

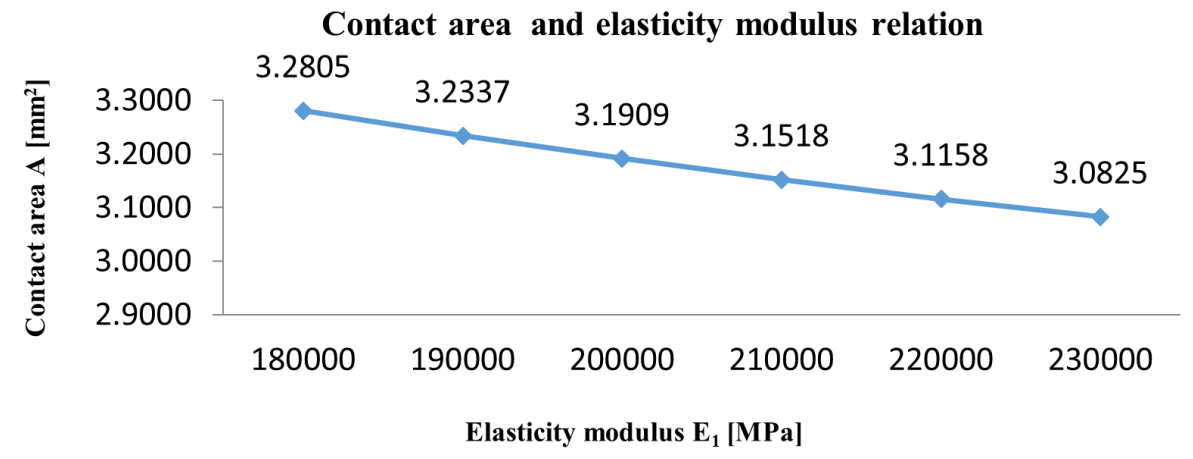

FiguRE 16. Relation between the contact area and elasticity modulus.

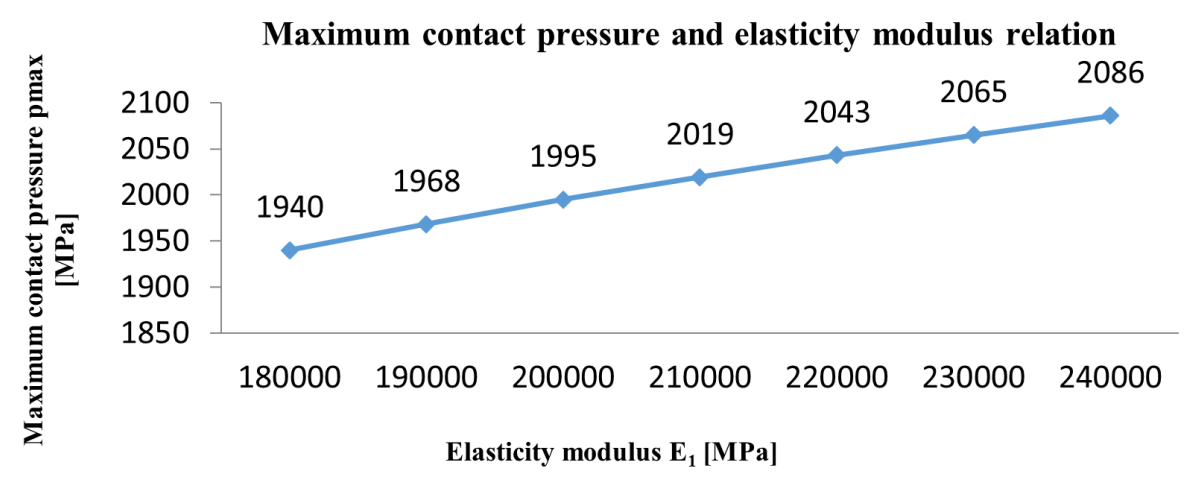

FIgURE 17. Relation between the maximum contact pressure and elasticity modulus.

\begin{tabular}{ccccc}
\hline $\begin{array}{c}d \\
{[\mathrm{~mm}]}\end{array}$ & $\begin{array}{c}D \\
{[\mathrm{~mm}]}\end{array}$ & $\begin{array}{c}B \\
{[\mathrm{~mm}]}\end{array}$ & $\begin{array}{c}D_{1} \\
{[\mathrm{~mm}]}\end{array}$ & $\begin{array}{c}F \\
{[\mathrm{~mm}]}\end{array}$ \\
\hline 70 & 110 & 20 & 95.7 & 90 \\
\hline
\end{tabular}

TABLE 7. Basic dimensions of standard NU 1014 roller bearing. 


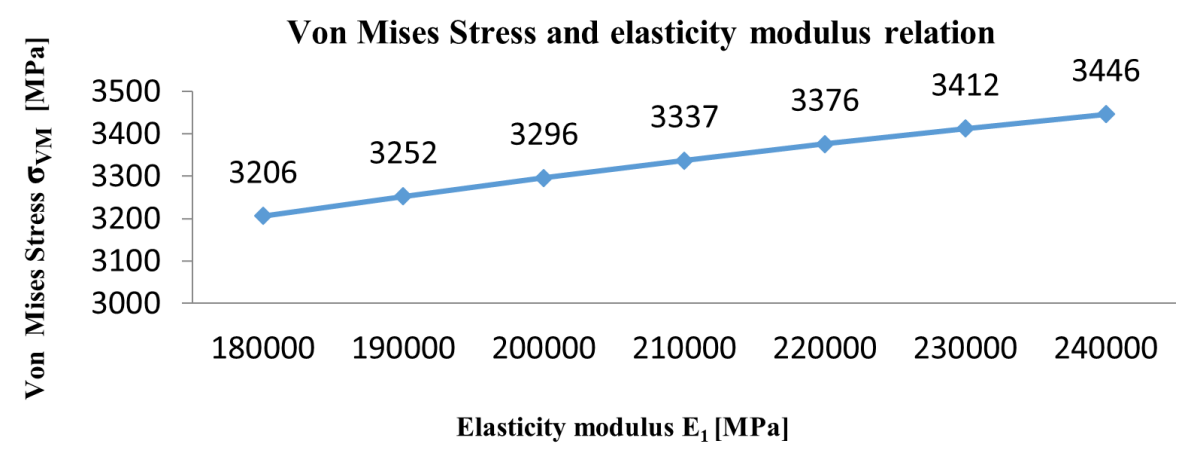

Figure 18. Relation between Von Mises Stress and elasticity modulus.

\begin{tabular}{ccccccc}
\hline $\begin{array}{c}R_{1} \\
{[\mathrm{~mm}]}\end{array}$ & $\begin{array}{c}R_{2} \\
{[\mathrm{~mm}]}\end{array}$ & $\begin{array}{c}\Re \\
{\left[\mathrm{mm}^{-1}\right]}\end{array}$ & $\begin{array}{c}a \\
{[\mathrm{~mm}]}\end{array}$ & $\begin{array}{c}A \\
{\left[\mathrm{~mm}^{2}\right]}\end{array}$ & $\begin{array}{c}p_{\max } \\
{[\mathrm{MPa}]}\end{array}$ & $\begin{array}{c}\sigma_{V M} \\
{[\mathrm{MPa}]}\end{array}$ \\
\hline 8.00 & 40 & 0.7050 & 0.1930 & 3.8601 & 1649 & 2725 \\
\hline
\end{tabular}

TABLE 8. Contact pressure and Von Mises stress results for standard NU 1014 roller bearings.

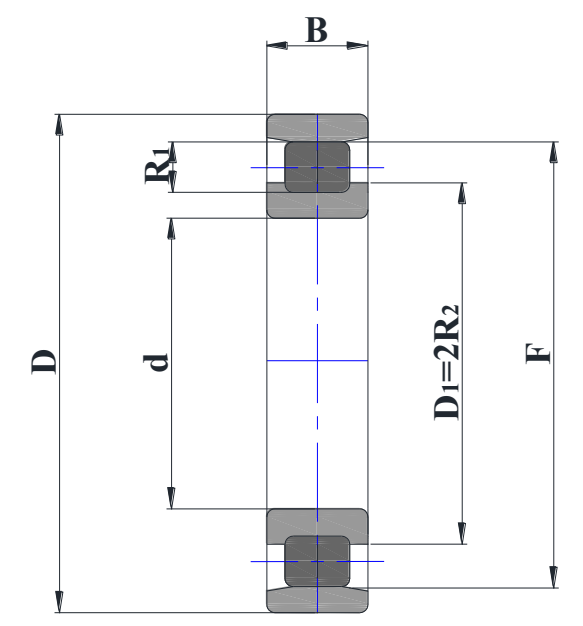

Figure 19. Basic Dimensions of NU 1014 roller bearing.

patch radius a from $0.1249[\mathrm{~mm}]$ to $0.1707[\mathrm{~mm}]$, as reported in Table 5

Increasing the elasticity modulus of the roller element $E_{1}$ from $180000\left[\mathrm{~N} / \mathrm{mm}^{2}\right]$ to $240000\left[\mathrm{~N} / \mathrm{mm}^{2}\right]$ results in a decreased contact area $A$ from $3.2805\left[\mathrm{~mm}^{2}\right]$ to $3.0825\left[\mathrm{~mm}^{2}\right]$ while keeping the geometry constant as constant. In contrast, increasing the elasticity modulus of the roller element $E_{1}$ results in a reduced contact-patch radius a from $0.1640[\mathrm{~mm}]$ to $0.1526[\mathrm{~mm}]$, as reported in Table 6 .

\section{Conclusion}

The purpose of this study is a theoretical investigation of the effects of design parameters on the static equivalent stress of radial rolling bearings, such as ball bearings and roller bearings.

For the point contact case of ball bearings and for the line contact case of roller bearings, the maximum contact pressure $p_{\max }$ for varying design parameters is calculated. The contact stress is calculated according to the Von Mises effective stress hypothesis.

The following results are obtained for the point contact case of a ball bearing application and for the line contact case of a roller bearing application:

(1.) Increasing the radius of the ball and roller elements $R_{1}$ results in a decreased geometry constant $\Re$. In contrast, increasing the radius of the ball and roller elements $R_{1}$ results in an increased contact area $A$, due to the increased contact-patch radius $a$.

(2.) Increasing the radius of the ball and roller elements results in a decreased maximum contact $p_{\max }$ and Von Mises effective stress $\sigma_{V M}$.

(3.) Increasing the elasticity modulus of the ball and roller elements $E_{1}$ results in a constant geometry constant $\Re$. In contrast, increasing the elasticity modulus of the ball and roller elements $E_{1}$ results in a decreased contact area $A$, due to the decreased contact-patch radius $a$.

(4.) Increasing the elasticity modulus of the ball and roller elements results in an increased maximum contact pressure $p_{\max }$ and Von Mises effective stress $\sigma_{V M}$, because of the decreased contact area.

The determination of the diameters and the selection of material of the ball and roller elements are crucial and play an effective role during the design process. Therefore, bearing designers and manufacturers should make the bearing geometrical dimensions as large as possible and the bearing material as elastic as possible. Furthermore, the stress-based static failure theory can also be used instead of the standard static load carrying capacity calculation. Moreover, von Mises stress theory is also compatible with the finite element method. 
The bearing static and dynamic load carrying capacity and bearing service life will be investigated by the author in a future study.

\section{REFERENCES}

[1] F. Sadeghi, B. Jalalahmadi, T. S. Slack, et al. A review of rolling contact fatigue. Journal of tribology 131(4):041403, 2009. DOI:10.1115/1.3209132

[2] R. Potočnik, P. Göncz, J. Flašker, S. Glodež. Fatigue life of double row slewing ball bearing with irregular geometry. Procedia engineering 2(1):1877 - 1886, 2010. DOI:10.1016/j.proeng.2010.03.202

[3] G. E. Morales-Espejel, A. Gabelli, A. J. C. de Vries. A model for rolling bearing life with surface and subsurface survival tribological effects. Tribology Transactions 58(5):894 - 906, 2015. DOI:10.1080/10402004.2015.1025932

[4] F. Kosugi. High-speed angular contact ball bearings new 9 series for machine tool. NTN Technical Review 78, 2010.

[5] J. Brändlein, P. Eschmann, L. Hasbargena, K. Weigand. Ball and Roller Bearings: Theory, Design and Application. John Wiley \& Sons, USA, 2000.

[6] M. Bozca. Theoretical investigation of point contact for ball bearings application. In ICMD 2016, 57th International Conference of Machine Design Departments, pp. 195 - 200. Železná Ruda, Czech Republic, 2016.

[7] M. Bozca. Theoretical investigation of line contact for roller bearings application. In ICMD 2016, 57th International Conference of Machine Design Departments, pp. 201 - 206. Železná Ruda, Czech Republic, 2016.

[8] M. Koç, M. Bozca. Finite elements method modelling of rolling bearings. Machines Technologies Materials 13(2):62 - 65, 2019.
[9] M. Yakout, M. G. A. Nassef, S. Backar. Effect of clearances in rolling element bearings on their dynamic performance, quality and operating life. Journal of Mechanical Science and Technology 33(5):2037 - 2042, 2019. DOI:10.1007/s12206-019-0406-y.

[10] F. B. Oswald, E. V. Zaretsky, J. V. Poplawski. Effect of internal clearance on load distribution and life of radially loaded ball and roller bearings. Tribology Transactions 55(2):245 - 265, 2012. DOI:10.1080/10402004.2011.639050.

[11] M. Yakout, A. Elkhatib, M. G. A. Nassef. Rolling element bearings absolute life prediction using modal analysis. Journal of Mechanical Science and Technology 32(1):91 - 99, 2018. DOI:10.1007/s12206-017-1210-1

[12] M. Belorit, S. Hrcek, L. Smetanka. Mathematical algorithm for calculating an optimal axial preload of rolling bearings with the respect to their life. In IOP Conference Series: Materials Science and Engineering, vol. 393, p. 012055. 2018. DOI:10.1088/1757-899X/393/1/012055.

[13] R. L. Norton. Machine design: An integrated approach. Pearson, New Jersey, USA, 4th edn., 2010.

[14] R. C. Juvinall, K. M. Marshek. Fundamentals of Machine Component Design. John Wiley \& Sons, 2006.

[15] R. G. Budynas, K. J. Nisbett. Shigley's Mechanical Engineering Design. McGraw-Hill, New York, USA, 9th edn., 2011.

[16] T. A. Harris, M. N. Kotzalas. Essential Concepts of Bearing Technology. CRC Press, New York, USA, 5th edn., 2007.

[17] H. Nguyen-Schäfer. Computational Design of Rolling Bearings. Springer International Publishing, Ludwigsburg, Germany, 2016. 